\title{
Continuous Wound Infiltration of Local Anesthetics in Postoperative Pain Management: Safety, Efficacy and Current Perspectives
}

This article was published in the following Dove Press journal:

Journal of Pain Research

\author{
Giuseppe Paladini (D) \\ Stefano Di Carlo (D) ${ }^{2}$ \\ Giuseppe Musella (D) \\ Emiliano Petrucci (D) $^{3}$ \\ Paolo Scimia (iD ${ }^{4}$ \\ Andrea Ambrosoli' \\ Vincenza Cofini $\mathbb{D D}^{5}$ \\ Pierfrancesco Fusco (1D $)^{3}$ \\ 'Department of Anesthesia, \\ Perioperative Medicine and Intensive \\ Care Therapy, Filippo Del Ponte Women \\ and Children's Hospital, ASST Sette \\ Laghi, Varese, Italy; ${ }^{2}$ Department of \\ Medical, Oral and Biotechnological \\ Sciences, University of Chieti, Chieti, \\ Italy; ${ }^{3}$ Department of Anesthesia and \\ Intensive Care, San Salvatore Academic \\ Hospital of L'Aquila, L'Aquila, Italy; \\ ${ }^{4}$ Department of Anesthesia and Intensive \\ Care, ASUR Marche AV5, San Benedetto \\ Del Tronto, Italy; ${ }^{5}$ Department of Life, \\ Health and Environmental Sciences, \\ University of L'Aquila, L'Aquila, Italy
}

\begin{abstract}
Local infiltration and continuous infusion of surgical wound with anesthetics are parts of multimodal analgesia for postoperative pain control. The techniques, given the simplicity of execution that does not increase the timing of the intervention and does not require additional technical skills, are applied in several kinds of surgeries. The continuous wound infiltration can be used for days and a variety of continuous delivery methods can be chosen, including patientcontrolled analgesia, continuous infusion or intermittent bolus. The purpose of this narrative review is to analyze the literature, in particular by researching the safety, efficacy and current perspectives of continuous wound infiltration for postoperative pain management in different surgical settings. We have identified 203 articles and 95 of these have been taken into consideration: 17 for the lower limb surgery; 7 for the upper limb surgery, 51 for the laparotomy/ laparoscopic surgery of the abdominopelvic area, 13 studies regarding breast surgery and 7 for cardiothoracic surgery. The analysis of these studies reveals that the technique has a variable effectiveness based on the type of structure involved: it is better in structures rich in subcutaneous and connective tissue, while the effectiveness is limited in anatomic districts with a greater variability of innervation. However, regardless the heterogeneity of results, a general reduction in pain intensity and in opioid consumption has been observed with continuous wound infiltration: it is an excellent analgesic technique that can be included in the multimodal treatment of postoperative pain or represents a valid alternative when other options are contraindicated.
\end{abstract}

Keywords: continuous wound infiltration, postoperative analgesia, postoperative pain management, local anesthetics

\section{Background}

Postoperative pain, particularly if moderate or severe, can cause serious complications that compromise the patient's outcome and lead to the development of chronic postoperative pain.

Often the goal of achieving a compliant analgesia is disregarded, whereby combinations of techniques are required to provide complete multimodal analgesia.

Therefore, a good intraoperative analgesia that encourages the use of multimodal strategies, including regional techniques, reduces postoperative hyperalgesia and the onset of chronic pain.

Local infiltration (Local Infiltration Anesthesia, LIA) and continuous infusion of surgical wound (Continuous Wound Infiltration, CWI) with anesthetics are techniques that have recently been reintroduced as integral parts of multimodal analgesia schemes for postoperative pain control.
Correspondence: Giuseppe Paladini Department of Anesthesia, Perioperative Medicine and Intensive Care Therapy, Filippo Del Ponte Women and Children's Hospital, ASST Sette Laghi, Via F. Del Ponte 19, Varese CAP 21 100, Italy

Tel $+393281477 \mid 89$

$\mathrm{Fax}+390332299299$

Email giuseppepaladinil6@gmail.com 
Intuition to irrigate the surgical wound with local anesthetic solutions is due to the research conducted in the early 1900s by Ewald Fulde and Walter Capelle. ${ }^{1}$

Subsequently, the two German surgeons focused attention on new methods that allowed both long-term pain control and early postoperative mobilization; developing, in 1930, the first CWI system. ${ }^{1}$

Continuous wound infusion is an effective, proven and safe analgesic technique that is simple to perform compared to other analgesic techniques, such as peripheral nerve blocks or epidural analgesia. ${ }^{2,3}$ It consists of an infusion of local anesthetic (LA) into wound through a catheter directly placed by the surgeon at the end of the procedure.

The CWI can be used for several days and, thanks to the development of new pumps, a variety of continuous delivery methods can be chosen, including patient-controlled analgesia, continuous infusion, or intermittent bolus. ${ }^{3}$

Currently, more and more studies are showing that CWI is able to reduce postoperative pain scores, need for opioids, hospitalization and to improve rehabilitation.

The purpose of this narrative review is to analyze the literature of the last decade on safety, efficacy and current perspectives of CWI for postoperative pain management in different surgical settings.

\section{Methods/Results}

A literature search was carried out including the following databases: Medline via PubMed, EMBASE, Ovid and the Cochrane Library covering the period from 2009 until August 2019.

We have included systematic review, meta-analysis and randomized controlled trials (RCTs).

Publications in English, French, German and Spanish have been considered.

The search strategy has included the following key words: "postoperative analgesia," "postoperative pain," "local anesthetics," "wound," "continuous infiltration," "continuous infusion," and "catheters". These key words and the corresponding MESH terms were combined with the Boolean operators "AND" and "OR."

We have excluded studies on cadaver, animal or artificial models. We have also excluded letters, comments, editorials, practice guidelines, case reports, and other studies with insufficient data.

Among 203 retrieved articles, 17 eligible studies have been found for the lower limb surgery; 7 for the upper limb surgery, 51 studies for the laparotomy/laparoscopic surgery of the abdominopelvic area, 13 studies regarding breast surgery and 7 for cardiothoracic surgery.

\section{Discussion}

\section{Lower Limb Surgery}

Several surgical procedures have been analyzed, including Total Hip Arthroplasty (THA), Total Knee Arthroplasty (TKA), ankle and foot surgery, burn reconstructive surgery, lower limb revascularization or amputation. ${ }^{4-20}$

Regarding THA, Fusco et al have conducted a doubleblind, randomized, controlled study with 96 patients. The patients were randomized to receive either a local infiltration analgesia and continuous wound infusion of $0.2 \%$ levobupivacaine (experimental group) or a local infiltration analgesia and continuous wound infusion of saline solution. The results have shown a significant effect of CWI on the postoperative incident of pain and on resting pain with a lower analgesic consumption and lower pain scores during the rehabilitation period. ${ }^{12}$

On the other hand, Solovyova et al in their prospective, double-blind, placebo-controlled study on 105 patients underwent THA, have shown no significant differences in the administration of opioids or in the pain scores between the group treated with LIA alone and the group treated with LIA followed by continuous infusion of ropivacaine. ${ }^{17}$

Aguirre et al have investigated the impact of a continuous wound infusion with ropivacaine $0.3 \%$ on pain and morphine consumption after minimally invasive hip arthroplasty in 76 patients. $^{4}$

When compared with placebo, the CWI has allowed a significant reduction in morphine consumption and a better postoperative analgesia. The beneficial effects of this technique were still present 3 months after surgery. ${ }^{4}$

No side effects have been reported in the abovementioned trials. ${ }^{4,12,17}$

CWI has been analyzed even in the context of knee arthroplasty giving heterogeneous results: when it has been compared to femoral nerve block, patient-controlled epidural analgesia (PCEA) or continuous epidural infusion of LA, it has provided a superior pain relief, an opioidsparing effect and a better recovery. ${ }^{6,7,11}$ As stated by Duggal, ${ }^{11}$ such benefits could lead to early mobilization/ rehabilitation or to decrease length of stay in patients with complex comorbidities indicated by higher ASA class.

On the other hand, the systematic review and metaanalysis (10 RCTs; 735 patients underwent TKA) by Sun et al has indicated that there is no significant difference 
in CWI or placebo treatment for pain at $48 \mathrm{hrs}$ with rest and at $72 \mathrm{hrs}$ with rest or mobilization. ${ }^{18}$

In addition, the most important finding of this study has been that CWI may also increase the rate of infection. ${ }^{18}$

Similar results have been obtained by Ali et al:

... continuous analgesia with ropivacaine after TKA has no relevant clinical effect on Visual Analogue Scale (VAS) pain and does not affect LOS, analgesic consumption, range of motion or leg-raising ability. There may, however, be a higher risk of wound-healing complications (including deep infections) during the first 3 months. ${ }^{5}$

Another side effect could be represented by knee chondrolysis when continuous intra-articular infusion of bupivacaine, with or without epinephrine, is set postoperatively. ${ }^{9,14}$

As regards the use of CWI for arthroscopic procedures, there are insufficient or not validated data in Literature.

Finally, CWI has also been used in corrective hallux surgery with no difference in pain control compared to placebo $^{8,15}$ and, outside of orthopedic surgery, in burn reconstructive surgery, lower limb revascularization or amputation allowing, in this case, an effective pain control and lower opioid consumption. ${ }^{13,16,19,20}$

\section{Laparotomy/Laparoscopic Surgery of the Abdominopelvic Area}

Given the heterogeneity of the different procedures and the different surgical settings, in this paragraph, we have preferred to consider the use of CWI in two macro-areas: open abdominal surgery and laparoscopic surgery.

As regards the first macro-area (laparotomy), all the analyzed studies agree in demonstrating the superiority of CWI compared to single-shot nerve blocks or placebo in ensuring better pain relief, lower opioid consumption, lower opioid-related side effects; enhancing, at the same time, the postoperative recovery. ${ }^{21-27}$

Unfortunately, the same conclusions cannot be drawn when CWI is compared to epidural analgesia (EA). In this field there is a high heterogeneity and, while some RCTs have shown a better or similar analgesic effect of CWI when compared to $\mathrm{EA},{ }^{28-35}$ others have claimed exactly the opposite ${ }^{36-38}$ often in the face of a higher incidence of side effects (ie, treatment failure, vasopressor requirement, prolonged recovery time) and higher costs. ${ }^{31,34,35,38-40}$

A meta-analysis of 2013 that included nine RCTs with a total of 505 patients has attempted to end this dilemma examining pain score at rest and on movement at $24 \mathrm{hrs}$ and $48 \mathrm{hrs}$, with subgroup analysis according to incision type and administration regimen (continuous versus bolus), opiate requirements, nausea and vomiting, urinary retention, catheter-related complications and treatment failure. $^{34}$

The authors have shown not significant differences between CWI and EA related to pain score at rest after $48 \mathrm{hrs}$, or on movement at 24 and $48 \mathrm{hrs}$ after surgery. Furthermore, CWI has allowed a reduced incidence of urinary retention in the postoperative period. ${ }^{34}$

Another systematic review and meta-analysis by Mungrop et al has tried to explain these conflicting results by analyzing the impact that the different location of wound catheters (ie, preperitoneal vs subcutaneous) could have on outcome. ${ }^{41}$

The Authors have shown a superiority of preperitoneal placement compared to subcutaneous placement with an analgesic power of the former as effective as epidural analgesia. $^{41}$

Perhaps, as stated by Rawal:

There is increasing evidence that less invasive regional analgesic techniques are as effective as epidural analgesia [...]. For routine postoperative analgesia, epidural analgesia may no longer be considered the gold standard. ${ }^{42}$

Further studies are certainly needed to clarify this hypothesis.

Certainly, in some particular settings, such as pediatric surgery or cesarean section, CWI has widely demonstrated its advantages both with respect to neuraxial analgesia than other techniques, guaranteeing excellent outcomes in terms of postoperative pain control, opioid demand, ease of execution, side effects. ${ }^{43-58}$

Regarding laparoscopic surgery, among 13 articles retrieved $^{59-71}$ most were related to laparoscopic colorectal surgery (9 out of 13). ${ }^{59-61,63-65,67,69,71}$

Similar to what has been demonstrated for open abdominal surgery, also in this case, CWI has demonstrated its effectiveness in the postoperative pain control, parental opioid consumption, rate of nausea/vomiting, early mobilization, bowel and pulmonary function; both when this technique has been compared with systemic or epidural analgesia. ${ }^{61,63,64,67,69,71}$

Furthermore, it would appear that continuous wound infusion with LA could also affect stress response and immunomodulation. $^{59,65}$ However, further studies are needed to elucidate this aspect.

As for other surgeries, Fassoulaki et al compared CWI with LA to CWI with saline solution in laparoscopic cholecystectomy. ${ }^{62}$ Pain at rest, pain during cough, and 
analgesic consumption have been recorded in the postanesthesia care unit and at 2, 4, 8, 24, and 48 hrs postoperatively. The authors have demonstrated good pain control up to $4 \mathrm{hrs}$ postoperatively. On the other hand, they have reported no benefit regarding late and chronic pain. $^{62}$

In another study, Kong et al have assessed the efficacy of analgesia provided by continuous ropivacaine wound infiltration after gynecologic laparoscopy, comparing it with IV-PCA (fentanyl plus ketorolac). ${ }^{66}$

Once again, CWI has shown to provide good analgesia with less opioid analgesic requirement and few adverse effects compared to IV-PCA, especially for PONV (The PONV scores at 12 and 24 hrs were, respectively, 0.28 and 0.27 in the CWI group, and 0.71 and 0.73 in the IV PCA group; $\mathrm{P}=0.004){ }^{66}$

In laparoscopic gastric bypass, no benefits have been reported by the study of Medbery et al. ${ }^{68}$

They have analyzed patient pain scores, postanesthesia care unit (PACU) times, postoperative narcotic and antiemetic requirements, postoperative complications, and hospital length of stay (LOS); but any difference has been found between patients with CWI and those without. ${ }^{68}$

Finally, Panaro et al have compared CWI with ropivacaine to intravenous opioids in patients who underwent laparoscopic living donor nephrectomy. ${ }^{70}$

They have observed a significant difference in terms of pain scores, use of morphine, hospital stay, and bowel recovery in favor of the CWI group. Unfortunately, one limitation of the study was the poor sample examined $(n=20){ }^{70}$

In conclusion, the use of the CWI for the surgery of abdominopelvic area, whether laparotomy or laparoscopy, offers numerous advantages in terms of analgesia, opioid consumption and early recovery, in accordance with ERAS (Enhanced Recovery After Surgery) protocols. ${ }^{72}$

On the other hand, the analysis of the various articles shows a certain heterogeneity in the results, probably due to several concurrent factors (ie, delivery methods, catheter location, volume or concentration of local anesthetic).

Perhaps the standardization of the procedures could be helpful in overcoming these biases and this goal could be achieved through further meta-analysis, systematic reviews or the drafting of new international guidelines that require, of course, a multidisciplinary and broad-spectrum approach.

\section{Upper Limb Surgery}

Traditionally, brachial plexus block is effectively used for the upper limb surgery, but local wound infiltration has been investigated; particularly in two settings: small ambulatory surgery (eg nerve decompression) and shoulder surgery.

A study of Fontana et al compared the analgesic efficacy of intraarticular injection, subacromial injection, interscalene block and intraarticular plus subacromial injection, associated with general anesthesia, for arthroscopic shoulder surgery. The analysis of this work shows that the interscalenic block is the technique that allows a better analgesia, with a lower VAS score and a lower demand for rescue analgesic drugs. However, the combination of intra-articular and subacromial infiltration allowed a valid level of analgesia with a lower analgesic consumption compared to the control group (intravenous analgesia) and the groups in which the techniques were used individually. Moreover, at 18 and 24 hrs postoperative follow-up the level of VAS pain and the detected Mean Satisfaction Score were similar between the interscalenic group and the intra-articular-subacromial infiltration group. Therefore, the authors conclude that the technique represents a valid alternative to the interscalenic block. $^{73}$

Another study by Koltka et al analyzed postoperative analgesia after continuous interscalenic block versus continuous infusion analgesia with catheter in the subacromial space. $^{74}$

Patients had the possibility of administering a bolus of local anesthetic using a PCI pump and could receive systemic analgesia rescue. Need for intravenous analgesia and consumption of local anesthetic were significantly lower in the interscalenic group. Even in this study, the authors underline the superiority of the interscalenic block and recommend its use up to contraindications. ${ }^{74}$

Merivirta et al compared subacromial LA infusion with placebo. The authors reported a moderate reduction of pain score, but, on the other hand, they underline the high consumption of analgesics and the risk of LAmediated chondrotoxicity, although there is not much evidence in this regard. ${ }^{75,76}$ Another study of Schwartzberg et al compared the analgesic efficacy of the subacromial local anesthetic infusion with placebo. The author did not find any difference in pain scores or analgesic consumption between subacromial infiltration and placebo. ${ }^{77}$

Probably, the limited effectiveness of this technique in the pain control is linked to the complex and rich innervation of the shoulder which is difficult to control through the infusion at the site of the surgical wound compared to what happens through the interscalenic infusion of the brachial plexus. 
As regards upper-extremity nerve decompression, Nabhan et al compared local anesthesia with intravenous regional anesthesia for endoscopic carpal tunnel release and reported no differences in pain scores but a longer tourniquet inflation time for the latter group. ${ }^{78}$ A systematic review about nerve decompression under local anesthesia confirmed the effectiveness of LA injection into the carpal tunnel, particularly when associated with anesthesia of subcutaneous plane. ${ }^{79}$ Although the authors did not find any evidence that long-acting LAs provide any advantages over short-acting LAs, they recommend the use of long-acting anesthetics since several studies underline its effectiveness in controlling postoperative pain. ${ }^{80}$ The use of epinephrine added to LAs is not recommended by the authors of the review. $^{79}$

Interestingly, the comparison of local wound infiltration (LWI) with peripheral nerve block in hand lacerations did not find any difference in terms of pain and satisfaction scores, but reported a shorter anesthesia onset time for LWI, that makes this technique, easier to perform compared to nerve block, particularly attractive in the emergency department. ${ }^{81}$

\section{Breast Surgery}

In this section, we have analyzed the results from 10 recent randomized trials reporting 927 cases of different breast surgery, including mastectomy with or without Immediate Tissue Expander Reconstruction, radical mastectomy, axillary node dissection, breast lump excision, wide local excision and reduction mammoplasty.

Pre-emptive local anesthesia, used at the surgical incision site in a patient undergoing mastectomy (with or without removal of the sentinel lymph node) compared with placebo, is associated with a lower mean pain score and a lower opioids consumption both in the intraoperative and postoperative phases with a relative reduction in cost and treatment. ${ }^{82-84}$

In the same way, continuous LA infusion through surgically placed wound catheters can conveniently prolong the pain control with reduced side effects including sedation, nausea and vomiting. ${ }^{85,86}$ Furthermore, the placement of continuous infusion catheters did not require additional surgical skills and the infusion pump or infusion catheter did not hinder patients during the postoperative stay. ${ }^{85}$

Compared to other local anesthesia techniques, Bouman et al did not find any difference in pain scores between continuous paravertebral block and continuous LA infusion after oncological breast surgery, pointing out that the latter may be preferable due to the lower incidence of associated complications. $^{87}$
Even delivering LAs through the surgical drain may have some advantages. ${ }^{88,89}$

Jonnavithula et al compared the instillation of $0.25 \%$ bupivacaine $40 \mathrm{~mL}$ ( $20 \mathrm{~mL}$ through each of the drain) with placebo. The drains were clamped for a period of $10 \mathrm{~min}$ after the drug administration. The technique was simple and effective in reducing postoperative pain and no technique-related complications were found. ${ }^{88}$

As regards the development of chronic postoperative pain, a qualitative systematic review that included 10 trials and 699 patients and a meta-analysis that analyzed 13 trials with 1150 patients confirm that continuous wound infiltration has an analgesic effect only in the first hours after surgery. ${ }^{90,91}$

Similar results were shown by the multicenter study of Albi-Feldzer et al, who evaluated the efficacy in postoperative pain control, the incidence of chronic postoperative pain and its consequences on quality of life and mood comparing the efficacy of preoperative infiltration of the wound at second and third intercostal spaces and at the humeral insertion of major pectoralis with placebo in 236 patients. The authors believe that the technique allows an effective pain control in the immediate postoperative period, especially in the first 90 mins, but - on the other hand - it does not bring benefits in persistent and chronic pain at 3, 6 and 12 months. ${ }^{92}$

An important study by Chiu et al compared paravertebral blockade with wound infusion (145 patients) in terms of persistent postoperative pain at 1 year after surgery. The authors reported a chronic postoperative pain incidence of only $8 \%$ in the sample of patients analyzed, much lower than the percentage reported in the literature of $25-60 \%{ }^{93}$

However, the study included both radical mastectomies and conservative surgeries; perhaps this may have influenced in reducing the incidence of persistent postoperative pain, as reported by the authors of the article.

Anyway, the regional techniques and the wound infiltration have shown to be effective in reducing the acute postoperative pain, which is one of the predisposing factors for the development of persistent pain. ${ }^{86,94,95}$

However, such results need to be confirmed by larger and well-designed randomized trials.

\section{Cardiothoracic Surgery}

Cardiothoracic surgery includes procedures ranging from thoracoscopy to thoracotomy-sternotomy: epidural or paravertebral block are effective analgesic techniques but can be associated with serious complications and requires more skills compared to LWI; moreover, the anticoagulation 
therapy often required after cardiac surgery can be a contraindication to neuraxial block. ${ }^{96}$

Both in thoracotomy and thoracoscopic surgery, LWI has shown a lower pain score, lower analgesic consumption, shorter postoperative hospital stays, higher patient satisfaction scores, earlier bowel canalization and ambulation when compared to no infiltration or placebo. ${ }^{97,98}$

On the other hand, Karnik et al, who compared local infiltration and systemic opioids in video-assisted thoracoscopic surgery decortication in pediatric empyema patients, affirmed that LWI is not as effective as epidural block in the reduction of postoperative pain. ${ }^{99}$

Similarly, Abo-zeid et al compared single-shot paravertebral block with local anesthetic infiltration in thoracoscopic surgery: the authors highlighted a considerable analgesic superiority of the para-neuraxial technique compared to the infiltration of the surgical site in terms of postoperative pain reduction, leading to a better respiratory function (FEV1). ${ }^{100}$

As regards to sternotomy, several authors suggested the continuous sternal infusion of LA for postoperative pain management, but data from published studies are conflicting: a study comparing continuous wound infusion versus placebo after sternotomy in 49 children did not find any difference in morphine consumption, pain score values, or nausea and vomiting. ${ }^{101}$ Conversely, a similar study on 40 adults reported a reduced pain score, reduced morphine consumption and improved rehabilitation but no differences in respiratory outcome associated with continuous LWI. ${ }^{102}$

The same authors confirmed the analgesic effect of CWI in a subsequent study, but did not found any difference in respiratory outcome or ICU length of stay. ${ }^{103}$

\section{Conclusion}

CWI is a simple technique, burdened with minimal incidence of complications, that can be applied to several kinds of surgeries. The technique does not require additional anesthetic or surgical skills and does not involve significant increases in the time of the procedure.

However, the type of surgery and the innervation of the structures involved can affect the effectiveness of the technique: the best results have probably been obtained in the treatment of cutaneous, subcutaneous and connective tissue structures, while the treatment of complex structures such as articulation and areas with multiple innervations has given lower results when compared to the reference regional techniques.
At the same time, regardless of this heterogeneity of results, a general reduction in pain intensity and in opioid consumption has been observed.

We believe that CWI is an excellent analgesic technique that can be included in the multimodal treatment of postoperative pain or represents a valid alternative when the other options are contraindicated.

\section{Acknowledgments}

The authors thank Stefano Necozione, MD, and Franco Marinangeli, MD (Department of Life, Health and Environmental Sciences, L'Aquila, Italy) for their assistance in revising the paper for important scientific content.

\section{Disclosure}

The authors report no conflicts of interest in this work.

\section{References}

1. Goerig M, Gottschalk A. Beginning of continuous wound infusion with local anesthetics: with special emphasis on the contributions from Walter Capelle and Ewald Fulde. Anaesthesist. 2017;66 (7):518-529. doi:10.1007/s00101-017-0285-5

2. Gottschalk A, Gottschalk A. Continuous wound infusion of local anesthetics: importance in postoperative pain therapy. Anaesthesist. 2010;59 (12):1076-1082. doi:10.1007/s00101-010-1808-5

3. Liu SS, Richman JM, Thirlby RC, Wu CL. Efficacy of continuous wound catheters delivering local anesthetic for postoperative analgesia: a quantitative and qualitative systematic review of randomized controlled trials. J Am Coll Surg. 2006;203(6):914-932. doi:10.1016/j. jamcollsurg.2006.08.007

4. Aguirre J, Baulig B, Dora C, et al. Continuous epicapsular ropivacaine $0.3 \%$ infusion after minimally invasive hip arthroplasty: a prospective, randomized, double-blinded, placebo-controlled study comparing continuous wound infusion with morphine patient-controlled analgesia. Anesth Analg. 2012;114(2):456-461. doi:10.1213/ANE.0b013e318239dc64

5. Ali A, Sundberg M, Hansson U, Malmvik J, Flivik G. Doubtful effect of continuous intraarticular analgesia after total knee arthroplasty: a randomized double-blind study of 200 patients. Acta Orthop. 2015;86 (3):373-377. doi:10.3109/17453674.2014.991629

6. Andersen KV, Bak M, Christensen BV, Harazuk J, Pedersen NA, Soballe K. A randomized, controlled trial comparing local infiltration analgesia with epidural infusion for total knee arthroplasty. Acta Orthop. 2010;81:606-610. doi:10.3109/17453674.2010.519165

7. Antoni M, Jenny JY, Noll E. Postoperative pain control by intra-articular local anesthesia versus femoral nerve block following total knee arthroplasty: impact on discharge. Orthop Traumatol Surg Res. 2014;100 (3):313-316. doi:10.1016/j.otsr.2013.12.022

8. Braito M, Dammerer D, Schlager A, Wansch J, Linhart C, Biedermann R. Continuous wound infiltration after hallux valgus surgery. Foot Ankle Int. 2018;39(2):180-188. doi:10.1177/1071100717736292

9. Buchko JZ, Gurney-Dunlop T, Shin JJ. Knee chondrolysis by infusion of bupivacaine with epinephrine through an intra-articular pain pump catheter after arthroscopic ACL reconstruction. Am J Sports Med. 2015;43(2):337-344. doi:10.1177/0363546514555667 
10. Dobrydnjov I, Anderberg C, Olsson C, Shapurova O, Angel K, Bergman S. Intraarticular vs. extraarticular ropivacaine infusion following high-dose local infiltration analgesia after total knee arthroplasty: a randomized double-blind study. Acta Orthop. 2011;82(6):692-698. doi:10.3109/17453674.2011.625535

11. Duggal S, Flics S, Cornell CN. Intra-articular analgesia and discharge to home enhance recovery following total knee replacement. HSS J. 2015;11(1):56-64. doi:10.1007/s11420-014-9414-8

12. Fusco P, Cofini V, Petrucci E, et al. Continuous wound infusion and local infiltration analgesia for postoperative pain and rehabilitation after total hip arthroplasty. Minerva Anestesiol. 2018;84 (5):556-564. doi:10.23736/S0375-9393.17.12110-3

13. Fuzaylov G, Kelly TL, Bline C, Dunaev A, Dylewski ML, Driscoll DN. Post-operative pain control for burn reconstructive surgery in a resource-restricted country with subcutaneous infusion of local anesthetics through a soaker catheter to the surgical site: preliminary results. Burns: J Int Soc for Burn Injuries. 2015;41(8):1811-1815. doi:10.1016/j.burns.2015.06.003

14. Noyes FR, Fleckenstein CM, Barber-Westin SD. The development of postoperative knee chondrolysis after intra-articular pain pump infusion of an anesthetic medication: a series of twenty-one cases. J Bone Joint Surg Am. 2012;94(16):1448-1457. doi:10.2106/JBJS.K.01333

15. Rose B, Kunasingam K, Barton T, Walsh J, Fogarty K, Wines A. A randomized controlled trial assessing the effect of a continuous subcutaneous infusion of local anesthetic following elective surgery to the great toe. Foot Ankle Spec. 2017;10(2):116-124. doi:10.1177/1938640016666923

16. Shutze W, Shutze Jr WP Jr., Prajapati P, et al. Postoperative continuous catheter-infused local anesthetic reduces pain scores and narcotic use after lower extremity revascularization. Vascular. 2018;26(3):262-270. doi:10.1177/1708538117728864

17. Solovyova O, Lewis $\mathrm{CG}$, Abrams JH, et al. Local infiltration analgesia followed by continuous infusion of local anesthetic solution for total hip arthroplasty: a prospective, randomized, double-blind, placebo-controlled study. J Bone Joint Surg Am. 2013;95(21):1935-1941. doi:10.2106/JBJS.L.00477

18. Sun XL, Zhao ZH, Ma JX, et al. Continuous local infiltration analgesia for pain control after total knee arthroplasty: a meta-analysis of randomized controlled trials. Medicine. 2015;94(45):e2005. doi:10.1097/MD.0000000000002005

19. Uhl C, Betz T, Rupp A, Steinbauer M, Topel I. The influence of continuous local wound infusion on postoperative pain in patients undergoing transfemoral amputation. VASA Zeitschrift fur Gefasskrankheiten. 2015;44(5):381-386. doi:10.1024/0301-1526/ $\mathrm{a} 000457$

20. Lundy JB, Cancio LC. A novel technique for split-thickness skin donor site pain control: subcutaneous catheters for continuous local anesthetic infusion. J Burn Care Res. 2012;33(1):e22-3. doi:10.1097/BCR.0b013e3182356095

21. Chan SK, Lai PB, Li PT, et al. The analgesic efficacy of continuous wound instillation with ropivacaine after open hepatic surgery. Anaesthesia. 2010;65(12):1180-1186. doi:10.1111/ana.2010.65 issue-12

22. Chaykovska L, Blohme L, Mayer D, et al. Paraincisional subcutaneous infusion of ropivacaine after open abdominal vascular surgery shows significant advantages. Ann Vasc Surg. 2014;28 (4):837-844. doi:10.1016/j.avsg.2013.11.019

23. Chung D, Lee YJ, Jo MH, et al. The ON-Q pain management system in elective gynecology oncologic surgery: management of postoperative surgical site pain compared to intravenous patient-controlled analgesia. Obstetrics Gynecol Sci. 2013;56 (2):93-101. doi:10.5468/OGS.2013.56.2.93

24. Dhanapal B, Sistla SC, Badhe AS, Ali SM, Ravichandran NT, Galidevara I. Effectiveness of continuous wound infusion of local anesthetics after abdominal surgeries. $J$ Surg Res. 2017;212:94-100. doi:10.1016/j.jss.2016.12.027
25. Gherghinescu MC, Copotoiu C, Lazar AE, Popa D, Mogoanta SS, Molnar C. Continuous local analgesia is effective in postoperative pain treatment after medium and large incisional hernia repair. Hernia: J Hernias Abdominal Wall Surg. 2017;21(5):677-685. doi:10.1007/s10029-017-1625-8

26. Hotta K, Inoue S, Taira K, Sata N, Tamai K, Takeuchi M. Comparison of the analgesic effect between continuous wound infiltration and single-injection transversus abdominis plane block after gynecologic laparotomy. $J$ Anesth. 2016;30(1):31-38. doi:10.1007/s00540-015-2083-z

27. Wang LW, Wong SW, Crowe PJ, et al. Wound infusion with local anaesthesia after laparotomy: a randomized controlled trial. $A N Z$ J Surg. 2010;80(11):794-801. doi:10.1111/ans.2010.80.issue-11

28. Araujo R. Pain management, local infection, satisfaction, adverse effects and residual pain after major open abdominal surgery: epidural versus continuous wound infusion (PAMA trial). Acta Med Port. 2017;30(10):683-690. doi:10.20344/amp.8600

29. Che L, Lu X, Pei LJ. Efficacy and safety of a continuous wound catheter in open abdominal partial hepatectomy. Chin Med Sci. 2017;32(3):171-176.

30. Fassoulaki A, Chassiakos D, Melemeni A. Intermittent epidural vs continuous wound infusion of ropivacaine for acute and chronic pain control after hysterectomy or myomectomy: a randomized controlled trial. Pain Med (Malden, Mass). 2014;15(9):1603-1608. doi:10.1111/pme.12523

31. Hughes MJ, Harrison EM, Peel NJ, et al. Randomized clinical trial of perioperative nerve block and continuous local anaesthetic infiltration via wound catheter versus epidural analgesia in open liver resection (LIVER 2 trial). $B r \quad J$ Surg. 2015;102 (13):1619-1628. doi:10.1002/bjs.9949

32. Kilic M, Ozkan Seyhan T, Orhan Sungur M, Ekiz N, Bastu E, Senturk M. The effects of subfascial wound versus epidural levobupivacaine infusion on postoperative pain following hysterectomy. Minerva Anestesiol. 2014;80(7):769-778.

33. Renghi A, Gramaglia L, Casella F, Moniaci D, Gaboli K, Brustia P. Local versus epidural anesthesia in fast-track abdominal aortic surgery. J Cardiothorac Vasc Anesth. 2013;27 (3):451-458. doi:10.1053/j.jvca.2012.09.026

34. Ventham NT, Hughes M, O’Neill S, Johns N, Brady RR, Wigmore SJ. Systematic review and meta-analysis of continuous local anaesthetic wound infiltration versus epidural analgesia for postoperative pain following abdominal surgery. $\mathrm{Br} J$ Surg. 2013;100(10):1280-1289. doi:10.1002/bjs.2013.100.issue-10

35. Mungroop TH, Veelo DP, Busch OR, et al. Continuous wound infiltration versus epidural analgesia after hepato-pancreatobiliary surgery (POP-UP): a randomised controlled, open-label, non-inferiority trial. Lancet Gastroenterol Hepatol. 2016;1 (2):105-113. doi:10.1016/S2468-1253(16)30012-7

36. Ammianickal PL, Thangaswamy CR, Balachander $\mathrm{H}$, Subbaiah M, Kumar NCP. Comparing epidural and wound infiltration analgesia for total abdominal hysterectomy: a randomised controlled study. Indian $J$ Anaesth. 2018;62(10):759-764. doi:10.4103/ija.IJA_124_18

37. Ball L, Pellerano G, Corsi L, et al. Continuous epidural versus wound infusion plus single morphine bolus as postoperative analgesia in open abdominal aortic aneurysm repair: a randomized non-inferiority trial. Minerva Anestesiol. 2016;82(12):1296-1305.

38. Revie EJ, McKeown DW, Wilson JA, Garden OJ, Wigmore SJ. Randomized clinical trial of local infiltration plus patient-controlled opiate analgesia vs. epidural analgesia following liver resection surgery. HPB: off J Int Hepato Pancreato Biliary Assoc. 2012;14(9):611-618. doi:10.1111/j.1477-2574.2012.00490.x

39. Bell R, Ward D, Jeffery J, et al. A randomized controlled trial comparing epidural analgesia versus continuous local anesthetic infiltration via abdominal wound catheter in open liver resection. Ann Surg. 2019;269(3):413-419. doi:10.1097/SLA.0000000000002988 
40. Tilleul P, Aissou M, Bocquet F, et al. Cost-effectiveness analysis comparing epidural, patient-controlled intravenous morphine, and continuous wound infiltration for postoperative pain management after open abdominal surgery. $B r \quad J$ Anaesth. 2012;108 (6):998-1005. doi:10.1093/bja/aes091

41. Mungroop TH, Bond MJ, Lirk P, et al. Preperitoneal or subcutaneous wound catheters as alternative for epidural analgesia in abdominal surgery: a systematic review and meta-analysis. Ann Surg. 2019;269 (2):252-260. doi:10.1097/SLA.0000000000002817

42. Rawal N. Epidural technique for postoperative pain: gold standard no more? Reg Anesth Pain Med. 2012;37(3):310-317. doi:10.1097/AAP.0b013e31825735c6

43. Hermansson O, George M, Wester T, Christofferson R. Local delivery of bupivacaine in the wound reduces opioid requirements after intraabdominal surgery in children. Pediatr Surg Int. 2013;29(5):451-454. doi:10.1007/s00383-013-3296-6

44. Krylborn J, Anell-Olofsson ME, Bitkover C, et al. Plasma levels of levobupivacaine during continuous infusion via a wound catheter after major surgery in newborn infants: an observational study. Eur $J$ Anaesthesiol. 2015;32(12):851-856. doi:10.1097/EJA.0000000000 000317

45. Machoki MS, Millar AJ, Albetyn H, Cox SG, Thomas J, Numanoglu A. Local anesthetic wound infusion versus standard analgesia in paediatric post-operative pain control. Pediatr Surg Int. 2015;31(11):1087-1097. doi:10.1007/s00383-015-3796-7

46. Niiyama Y, Yotsuyanagi T, Yamakage M. Continuous wound infiltration with $0.2 \%$ ropivacaine versus a single intercostal nerve block with $0.75 \%$ ropivacaine for postoperative pain management after reconstructive surgery for microtia. J Plast Reconstructive Aesthetic Surg. 2016;69(10):1445-1449. doi:10.10 16/j.bjps.2016.05.009

47. Chandon M, Bonnet A, Burg Y, et al. Ultrasound-guided transversus abdominis plane block versus continuous wound infusion for post-caesarean analgesia: a randomized trial. PLoS One. 2014;9(8):e103971. doi:10.1371/journal.pone.0103971

48. Eldaba AA, Amr YM, Sobhy RA. Effect of wound infiltration with bupivacaine or lower dose bupivacaine/magnesium versus placebo for postoperative analgesia after cesarean section. Anesthesia Essays Res. 2013;7(3):336-340. doi:10.4103/0259-1162.123227

49. Fustran Guerrero N, Dalmau Llitjos A, Sabate Pes A. Continuous infusion of local anesthetic at the site of the abdominal surgical wound for postoperative analgesia: a systematic review. Rev Esp Anestesiol Reanim. 2011;58(6):337-344. doi:10.1016/S00349356(11)70082-2

50. Jolly C, Jathieres F, Keita H, Jaouen E, Guyot B, Torre A. Cesarean analgesia using levobupivacaine continuous wound infiltration: a randomized trial. Eur J Obstet Gynecol Reprod Biol. 2015;194:125-130. doi:10.1016/j.ejogrb.2015.08.023

51. Klasen F, Bourgoin A, Antonini F, et al. Postoperative analgesia after caesarean section with transversus abdominis plane block or continuous infiltration wound catheter: a randomized clinical trial. TAP Vs. Infiltration After Caesarean Section. Anaesth Crit Care Pain Med. 2016;35(6):401-406. doi:10.1016/j.accpm.2016.02.006

52. Lalmand M, Wilwerth M, Fils JF, van der Linden P. Continuous ropivacaine subfascial wound infusion compared with intrathecal morphine for postcesarean analgesia: a prospective, randomized controlled, double-blind study. Anesth Analg. 2017;125 (3):907-912. doi:10.1213/ANE.0000000000001892

53. O’Neill P, Duarte F, Ribeiro I, Centeno MJ, Moreira J. Ropivacaine continuous wound infusion versus epidural morphine for postoperative analgesia after cesarean delivery: a randomized controlled trial. Anesth Analg. 2012;114 (1):179-185. doi:10.1213/ANE.0b013e3182368e87

54. Patel SD, Sharawi N, Sultan P. Local anaesthetic techniques for post-caesarean delivery analgesia. Int $J$ Obstet Anesth. 2019;40:62-77. doi:10.1016/j.ijoa.2019.06.002
55. Rackelboom T, Le Strat $\mathrm{S}$, Silvera $\mathrm{S}$, et al. Improving continuous wound infusion effectiveness for postoperative analgesia after cesarean delivery: a randomized controlled trial. Obstet Gynecol. 2010;116(4):893-900. doi:10.1097/AOG.0b013e3181 f38ac6

56. Telnes A, Skogvoll E, Lonnee H. Transversus abdominis plane block vs. wound infiltration in Caesarean section: a randomised controlled trial. Acta Anaesthesiol Scand. 2015;59(4):496-504. doi:10.1111/aas.2015.59.issue-4

57. Wagner-Kovacec J, Povalej-Brzan P, Mekis D. Efficacy of continuous in-wound infusion of levobupivacaine and ketorolac for post-caesarean section analgesia: a prospective, randomised, double-blind, placebo-controlled trial. BMC Anesthesiol. 2018;18(1):165. doi:10.1186/s12871-018-0609-2

58. Zaretsky M, Wood C, Nivens T, et al. Continuous local bupivacaine wound infusion with neuraxial morphine reduces opioid consumption after cesarean delivery. Journal Maternal-Fetal Neonatal Med. 2019;32(23):3895-3902. doi:10.1080/ 14767058.2018.1474872

59. Barr J, Boulind C, Foster JD, et al. Impact of analgesic modality on stress response following laparoscopic colorectal surgery: a post-hoc analysis of a randomised controlled trial. Tech Coloproctol. 2015;19 (4):231-239. doi:10.1007/s10151-015-1270-0

60. Beaussier M, Parc Y, Guechot J, Cachanado M, Rousseau A, Lescot T. Ropivacaine preperitoneal wound infusion for pain relief and prevention of incisional hyperalgesia after laparoscopic colorectal surgery: a randomized, triple-arm, double-blind controlled evaluation vs intravenous lidocaine infusion, the CATCH study. Colorectal Dis. 2018;20 (6):509-519. doi:10.1111/codi.2018.20.issue-6

61. Boulind CE, Ewings P, Bulley SH, et al. Feasibility study of analgesia via epidural versus continuous wound infusion after laparoscopic colorectal resection. $B r \quad J \quad$ Surg. 2013;100 (3):395-402. doi:10.1002/bjs.v100.3

62. Fassoulaki A, Vassi E, Korkolis D, Zotou M. Perioperative continuous ropivacaine wound infusion in laparoscopic cholecystectomy: a randomized controlled double-blind trial. Surg Laparosc Endosc Percutan Tech. 2016;26(1):25-30. doi:10.1097/SLE.00000000000 00224

63. Fustran N, Dalmau A, Ferreres E, et al. Postoperative analgesia with continuous wound infusion of local anaesthesia vs saline: a double-blind randomized, controlled trial in colorectal surgery. Colorectal Dis. 2015;17(4):342-350. doi:10.1111/codi.12893

64. Helander EM, Webb MP, Bias M, Whang EE, Kaye AD, Urman RD. Use of regional anesthesia techniques: analysis of institutional enhanced recovery after surgery protocols for colorectal surgery. J Laparoendosc Adv Surg Tech A. 2017;27 (9):898-902. doi:10.1089/lap.2017.0339

65. Kim SY, Kim NK, Baik SH, et al. Effects of postoperative pain management on immune function after laparoscopic resection of colorectal cancer: a randomized study. Medicine. 2016;95(19): e3602. doi:10.1097/MD.0000000000003602

66. Kong TW, Park H, Cheong JY, Min SK, Ryu HS. Efficacy of continuous wound infiltration of local anesthetic for pain relief after gynecologic laparoscopy. Int J Gynaecol Obstet. 2014;124 (3):212-215. doi:10.1016/j.ijgo.2013.08.019

67. Lee SH, Sim WS, Kim GE, et al. Randomized trial of subfascial infusion of ropivacaine for early recovery in laparoscopic colorectal cancer surgery. Korean J Anesthesiol. 2016;69(6):604-613. doi:10.4097/kjae.2016.69.6.604

68. Medbery RL, Chiruvella A, Srinivasan J, Sweeney JF, Lin E, Davis SS. The value of continuous wound infusion systems for postoperative pain control following laparoscopic Roux-en-Y gastric bypass: an analysis of outcomes and cost. Obes Surg. 2014;24(4):541-548. doi:10.1007/s11695-0131110-0 
69. Oh BY, Park YA, Koo HY, et al. Analgesic efficacy of ropivacaine wound infusion after laparoscopic colorectal surgery. Ann Surg Treat Res. 2016;91(4):202-206. doi:10.4174/astr.2016.91.4.202

70. Panaro F, Gheza F, Piardi T, et al. Continuous infusion of local anesthesia after living donor nephrectomy: a comparative analysis. Transplant Proc. 2011;43(4):985-987. doi:10.1016/j. transproceed.2011.01.144

71. Telletxea S, Gonzalez J, Portugal V, et al. Analgesia with interfascial continuous wound infiltration after laparoscopic colon surgery: a randomized clinical trial. Rev Esp Anestesiol Reanim. 2016;63(4):197-206. doi:10.1016/j.redar.2015.07.008

72. Ljungqvist $\mathrm{O}$, Scott $\mathrm{M}$, Fearon KC. Enhanced recovery after surgery: a review. JAMA Surg. 2017;152(3):292-298. doi:10.1001/jamasurg.2016.4952

73. Fontana C, Di Donato A, Di Giacomo G, et al. Postoperative analgesia for arthroscopic shoulder surgery: a prospective randomized controlled study of intraarticular, subacromial injection, interscalenic brachial plexus block and intraarticular plus subacromial injection efficacy. Eur J Anaesthesiol. 2009;26 (8):689-693. doi:10.1097/EJA.0b013e32832d673e

74. Koltka K, Doğruel B, Sentürk M, Atalar AC, Küçükay S, Pembeci K. Postoperative analgesia for arthroscopic rotator cuff surgery: a comparison between subacromial and interscalene levobupivacaine. Agri. 2011;23(1):7-12. doi:10.5505/ agri.2011.97269

75. Merivirta R, Kuusniemi KS, Aantaa R, Hurme SA, Aärimaa V, Leino KA. The analgesic effect of continuous subacromial bupivacaine infusion after arthroscopic shoulder surgery: a randomized controlled trial. Acta Anaesthesiol Scand. 2012;56 (2):210-216. doi:10.1111/aas.2012.56.issue-2

76. Busfield B, Romero D. Pain pump use after shoulder arthroscopy as a cause of glenohumeral chondrolysis. Arthroscopy. 2009;25 (6):647-652. doi:10.1016/j.arthro.2009.01.019

77. Schwartzberg RS, Reuss BL, Rust R. Efficacy of continuous subacromial bupivacaine infusion for pain control after arthroscopic rotator cuff repair. J Shoulder Elbow Surg. 2013;22 (10):1320-1324. doi:10.1016/j.jse.2013.03.016

78. Nabhan A, Steudel WI, Dedeman L, Al-Khayat J, Ishak B. Subcutaneous local anesthesia versus intravenous regional anesthesia for endoscopic carpal tunnel release: a randomized controlled trial. J Neurosurg. 2011;114(1):240-244. doi:10.3171/ 2008.2.17395

79. Chocron Y, Aljerian A, Thibaudeau S. Upper-Extremity Nerve Decompression Under Local Anesthesia: A Systematic Review of Methods for Reduction of Postoperative Pain and Opioid Consumption. New York, NY: Hand; 2019:1558944719843635.

80. Keramidas EG, Rodopoulou SG. Ropivacaine versus lidocaine in digital nerve blocks: a prospective study. Plast Reconstr Surg. 2007;119(7):2148-2152. doi:10.1097/01.prs.0000260725.33655.88

81. Şener A, Demircan A, Keleş A, Bildik F, Karakurt K. Comparison of local infiltration anesthesia and peripheral nerve block: a randomized prospective study in hand lacerations. Turk J Med Sci. 2015;45(3):694-699. doi:10.3906/sag-1312-24

82. Zielinski J, Jaworski R, Smietanska I, Irga N, Wujtewicz M, Jaskiewicz J. A randomized, double-blind, placebo-controlled trial of preemptive analgesia with bupivacaine in patients undergoing mastectomy for carcinoma of the breast. Med Sci Monit. 2011;17(10):CR589-97. doi:10.12659/MSM.881986

83. Vigneau A, Salengro A, Berger J, et al. A double blind randomized trial of wound infiltration with ropivacaine after breast cancer surgery with axillary nodes dissection. BMC Anesthesiol. 2011;24(11):23. doi:10.1186/1471-2253-11-23

84. Campbell I, Cavanagh S, Creighton J, et al. To infiltrate or not? Acute effects of local anaesthetic in breast surgery. ANZ J Surg. 2015;85(5):353-357. doi:10.1111/ans.2015.85.issue-5
85. Raghavendra GK, Sreenivasa RH, Ashok K, et al. Surgically placed wound catheters (SPWC) and local anaesthetic infusion in breast surgery: efficacy and safety analysis. Breast Dis. 2011;33(1):1-8. doi:10.3233/BD-2010-0316

86. Strazisar B, Besic N. Comparison of continuous local anaesthetic and systemic pain treatment after axillary lymphadenectomy in breast carcinoma patients - a prospective randomized study. Radiol Oncol. 2013;47(2):145-153. doi:10.2478/raon-2013-0018

87. Bouman EA, Theunissen M, Kessels AG, et al. Continuous paravertebral block for postoperative pain compared to general anaesthesia and wound infiltration for major oncological breast surgery. Springerplus. 2014;11(3):517. doi:10.1186/2193-1801-3-517

88. Jonnavithula N, Khandelia H, Durga P, Ramachandran G. Role of wound instillation with bupivacaine through surgical drains for postoperative analgesia in modified radical mastectomy. Indian J Anaesth. 2015;59(1):15-20. doi:10.4103/0019-5049. 149443

89. Khpal M, Miller JRC, Petrovic Z, Hassanally D. Local anesthetic delivery via surgical drain provides improved pain control versus direct skin infiltration following axillary node dissection for breast cancer. Breast Cancer. 2018;25(2):185-190. doi:10.1007/ s12282-017-0810-z

90. Byager N, Hansen MS, Mathiesen O, Dahl JB. The analgesic effect of wound infiltration with local anaesthetics after breast surgery: a qualitative systematic review. Acta Anaesthesiol Scand. 2014;58(4):402-410. doi:10.1111/aas.2014.58.issue-4

91. Tam KW, Chen SY, Huang TW, et al. Effect of wound infiltration with ropivacaine or bupivacaine analgesia in breast cancer surgery: a meta-analysis of randomized controlled trials. Int J Surg. 2015;22:79-85. doi:10.1016/j.ijsu.2015.07.715

92. Albi-Feldzer A, Mouret-Fourme EE, Hamouda S, et al. A double-blind randomized trial of wound and intercostal space infiltration with ropivacaine during breast cancer surgery: effects on chronic postoperative pain. Anesthesiology. 2013;118 (2):318-326. doi:10.1097/ALN.0b013e31827d88d8

93. Chiu M, Bryson GL, Lui A, Watters JM, Taljaard M, Nathan HJ. Reducing persistent postoperative pain and disability 1 year after breast cancer surgery: a randomized, controlled trial comparing thoracic paravertebral block to local anesthetic infiltration. Ann Surg Oncol. 2014;21(3):795-801. doi:10.1245/s10434-013-3334-6

94. Jung BF, Ahrendt GM, Oaklander AL, Dworkin RH. Neuropathic pain following breast cancer surgery: proposed classification and research update. Pain. 2003;104(1-2):1-13. doi:10.1016/S03043959(03)00241-0

95. Syal K, Chandel A. Comparison of the post-operative analgesic effect of paravertebral block, pectoral nerve block and local infiltration in patients undergoing modified radical mastectomy: a randomised double-blind trial. Indian J Anaesth. 2017;61 (8):643-648. doi:10.4103/ija.IJA_81_17

96. Svircevic V, van Dijk D, Nierich AP, et al. Meta-analysis of thoracic epidural anesthesia versus general anesthesia for cardiac surgery. Anesthesiology. 2011;114(2):271-282. doi:10.1097/ ALN.0b013e318201d300

97. Fiorelli A, Vicidomini G, Laperuta P, et al. Pre-emptive local analgesia in video-assisted thoracic surgery sympathectomy. Eur $J$ Cardiothorac Surg. 2010;37(3):588-593. doi:10.1016/j.ejcts. 2009.07.040

98. Rao Z, Zhou H, Pan X, et al. Ropivacaine wound infiltration: a fast-track approach in patients undergoing thoracotomy surgery. J Surg Res. 2017;220:379-384. doi:10.1016/j.jss.20 17.05 .082

99. Karnik PP, Dave NM, Garasia M. Comparison of analgesic efficacy and safety of continuous epidural infusion versus local infiltration and systemic opioids in video-assisted thoracoscopic surgery decortication in pediatric empyema patients. Saudi J Anaesth. 2018;12(2):240-244. doi:10.4103/sja.SJA_659_17 
100. Abo-Zeid MA, Elgamal MM, Hewidy AA, Moawad AA, Adel Elmaddawy AE. Ultrasound-guided multilevel paravertebral block versus local anesthesia for medical thoracoscopy. Saudi J Anaesth. 2017;11(4):442-448. doi:10.4103/sja. SJA_292_17

101. Mattila I, Pätilä T, Rautiainen P, et al. The effect of continuous wound infusion of ropivacaine on postoperative pain after median sternotomy and mediastinal drain in children. Paediatr Anaesth. 2016;26(7):727-733. doi:10.1111/pan.2016.26.issue-7
102. Eljezi V, Dualé C, Azarnoush K, et al. The analgesic effects of a bilateral sternal infusion of ropivacaine after cardiac surgery. Reg Anesth Pain Med. 2012;37(2):166-174. doi:10.1097/ AAP.0b013e318240957f

103. Eljezi V, Imhoff E, Bourdeaux D, et al. Bilateral sternal infusion of ropivacaine and length of stay in ICU after cardiac surgery with increased respiratory risk: a randomised controlled trial. Eur J Anaesthesiol. 2017;34(2):56-65. doi:10.1097/EJA.000000000000 0564

\section{Publish your work in this journal}

The Journal of Pain Research is an international, peer reviewed, open access, online journal that welcomes laboratory and clinical findings in the fields of pain research and the prevention and management of pain. Original research, reviews, symposium reports, hypothesis formation and commentaries are all considered for publication. The manuscript

Submit your manuscript here: https://www.dovepress.com/journal-of-pain-research-journal management system is completely online and includes a very quick and fair peer-review system, which is all easy to use. Visit http:// www.dovepress.com/testimonials.php to read real quotes from published authors. 